\title{
GESTÃQ EDUCACIONAL E SUA RELACÁO COM A OFERTA DE ATIVIDADES COMPLEMENTARES CURRICULARES
}

\author{
EDUCATIONAL MANAGEMENT AND ITS RELATIONSHIP WITH THE OFFER OF \\ CURRICULAR ACTIVITIES COMPLEMENT
}

\author{
GESTIÓN EDUCACIONAL Y SU RELACIÓN CON LA OFERTA DE ACTIVIDADES \\ COMPLEMENTARES CURRICULARES
}

Eduard Angelo Bendrath bendrath@gmail.com

\author{
Andreia Paula Basei \\ andreiabasei@yahoo.com.br \\ Jessica Latchuk Frederico \\ jessicalatchuk@hotmail.com \\ REVISTA PEDAGÓGICA
}

Revista do Programa de Pós-graduação em Educação da Unochapecó | ISSN 1984-1566

Universidade Comunitária da Região de Chapecó | Chapecó-SC, Brasil Como referenciar este artigo: BENDRATH, E. A.; BASEI, A. P.; FREDERICO, J. L. Gestão educacional e sua relação com a oferta de atividades complementares curriculares. Revista Pedagógica, Chapecó, v. 20, n. 44, p. 197-215, mai./ago. DOI: http://dx.doi.org/10.22196/rp.v20i44.4041

RESUMO: A oferta de atividades paralelas ao sistema formal de ensino como mecanismo para ampliação da jornada escolar e possibilidade de melhoria da qualidade educacional já é uma realidade no atual cenário nacional. No estado do Paraná o Programa Atividades Complementares Curriculares possibilita às escolas estaduais ofertarem atividades de contraturno em diversos eixos temáticos. Dessa forma, o objetivo desse estudo foi compreender a dinâmica dessas atividades em escolas de um município de pequeno porte do Estado tendo como foco de observação o papel do gestor na condução das ações. Foram coletados dados quantitativos de desenvolvimento das ações nas escolas, bem como, realizadas entrevistas semiestruturadas com os gestores das unidades pesquisadas. Os dados mostraram que há uma efetiva participação dos alunos no programa, mas que há dificuldades dos gestores em compreenderem os processos específicos da proposta, tanto em termos pedagógicos quanto administrativos.

Palavras-chave: Gestão Educacional; Atividades Complementares Curriculares; Escola de Tempo Integral.

ABSTRACT: The offer of activities in parallel to the formal system of education as a mechanism for extending the school day and the possibility of improving the quality of education is already a reality in the current national scenario. In Paraná State the Program of Curricular Activities Complement enables to state schools to develop activities of Extra-Curricular in several thematic axes. Thus, the objective of this study was to understand the dynamics of these activities in a small city in the state having as a focus for the observation of the role of the educational manager in the conduct of actions. Data quantitative were collected in development of actions in schools and were too carried out semi-structured interviews with the educational managers of units surveyed. The data showed that there is an effective participation of students in the program, but that there are difficulties of managers in understanding the specific processes of the proposal, both in terms of pedagogical and administrative.

Keywords: Educational Management; Curricular Activities Complement; Full-time education

RESUMÉN: La oferta de actividades paralelas al sistema formal de enseñanza como mecanismo para ampliación de la jornada escolar y posibilidad de mejora de la calidad educativa ya es una realidad en el actual escenario nacional. En el estado de Paraná el Programa de Actividades Curriculares Complementares posibilita a las escuelas estatales ofertar actividades de contra turno en diversos ejes temáticos. De esta forma, el objetivo de este estudio fue comprender la dinámica de esas actividades en una ciudad de pequeño porte del estado teniendo como foco de observación el papel del gestor en la conducción de las acciones. Se recogieron datos técnicos cuantitativos de desarrollo de las acciones en las escuelas así como se realizaron entrevistas semiestructuradas con los gestores de las unidades investigadas. Los datos mostraron que hay una efectiva participación de los alumnos en el programa, pero que hay dificultades de los gestores en comprender los procesos específicos de la propuesta, tanto en términos pedagógicos y administrativos.

Palabras-clave: Gestión educativa; Actividades Curriculares Complementarias; Educación Integral. 


\section{INTRODUÇÃO}

O objetivo deste trabalho foi compreender a dinâmica pela qual as Atividades Complementares Curriculares (ACCs) estão inseridas nas escolas estaduais de um município do interior do Paraná tendo como principal ponto de articulação o papel do gestor frente às propostas.

Para tanto, propomos uma reflexão acerca do papel da liderança escolar, especificamente no que se refere ao papel do gestor escolar e a forma como ele compreende e sistematiza as ACCs como possibilidade educativa associada à educação básica. Partimos para a compreensão do fenômeno a partir de quatro fatores centrais: 1) o papel da gestão junto às ACCs; 2) a tomada de decisão e forma de seleção das ACCs na escola; 3) o gerenciamento de recursos e; 4) o acompanhamento de ações.

No que tange a especificidade das ACCs no Paraná, destaca-se que há uma política da Secretaria de Estado da Educação (SEED) de valorização de tais iniciativas, sendo as mesmas amparadas por normativas legais. A Resolução n. 1.690/2011 SEED e a Instrução Normativa n. 07/2012SEED balizam todas as iniciativas das escolas estaduais paranaenses no sentido de assegurar a execução de projetos de contraturno escolar a partir de seus objetivos diretos.

Compreendendo tal panorama, a SEED posiciona as ACCs como atividades educativas integradas ao currículo escolar e contempladas no Projeto Político Pedagógico/Proposta Pedagógica Curricular da escola (PARANÁ, 2012, p.1). O objetivo destas atividades é a melhoria da qualidade do ensino por meio da ampliação de tempos, espaços e oportunidades educativas realizadas na escola ou no território onde está situada, em contraturno, a fim de atender às necessidades socioeducacionais dos alunos (PARANÁ, 2011).

Neste contexto, o papel da gestão escolar torna-se essencial para estabelecer uma ligação efetiva entre os conteúdos da educação básica e uma proposta educacional em contraturno evidenciada pelas necessidades socioeducacionais da comunidade escolar. Dessa forma, o nosso questionamento inicial parte da perspectiva de compreender como as ACCs são desenvolvidas e como os gestores sistematizam tais ações dentro do ambiente escolar.

\section{DEFININDO A GESTÃO ESCOLAR}

1 Optamos por manter a dupla terminologia Administração/Gestão em virtude de entendermos que o processo de organização da escola engloba elementos constitutivos, tanto práticos quanto teóricos, de ambos os termos.
Compreendemos que a gestão/administração ${ }^{1}$ escolar não pode ser observada apenas considerando modelos pré-importados de outras organizações. Esse posicionamento é impetrado quando observamos a possibilidade dos processos administrativos escolares se comportarem como processos administrativos empresariais.

No entanto, a natureza das bases teóricas que sustentaram a administração/gestão escolar indicam caminhos diferentes para os mesmos objetivos, em linhas gerais 
a ampliação do acesso e melhoria da qualidade do ensino ofertado. Dessa forma, nos propomos a apresentar duas concepções gerais que nortearam a construção do modelo de organização escolar brasileira: a concepção técnico-científica e a concepção sociocrítica.

A concepção técnico-científica parte do entendimento de um modelo organizacional amparado por pressupostos da teoria administrativa clássica e remonta a década de 1930 onde os ideais progressistas floreavam no cenário educacional brasileiro. É nesse período que a trajetória da administração da educação toma um novo rumo, começamos a escrever um novo capítulo no campo da administração da educação (SANDER, 2007, p. 425). De acordo com Drabach e Mousquer (2009), esse período foi fortemente influenciado pela corrente progressista norte-americana capitaneada por John Dewey e que originou no Brasil o movimento pedagógico da Escola Nova que teve como alguns de seus protagonistas os educadores Lourenço Filho, Anísio Teixeira e José Querino Ribeiro.

Dentro da perspectiva da organização escolar, o movimento prezava pela maior cientificidade dos processos gerenciais bem como a ampliação da oferta educacional para a sociedade. Segundo Drabach e Mousquer:

Data deste período, o Manifesto dos Pioneiros da Educação Nova que mencionava, dentre outras questões, a falta de espírito filosófico e científico na resolução dos problemas da administração escolar como principal responsável pela desorganização do aparelho escolar (DRABACH, MOUSQUER, 2009, p.260).

O posicionamento da organização escolar posta pelos educadores do movimento pedagógico da Escola Nova é considerado por Sander (1995) como um movimento amparado pela abordagem da teoria clássica da administração tendo como viés uma perspectiva tecnocrática. Esse entendimento perdurou durante muitos anos e esteve fortemente associado ao modelo de desenvolvimento nacional que vigorara.

Para os autores do manifesto o sistema educacional brasileiro deveria estar amparado nos pressupostos da laicidade, do acesso público, obrigatório e gratuito para toda a população. Esse pensamento trouxe um paradigma ao sistema educacional, uma vez que, não havia estrutura para a oferta de ensino dentro de tais perspectivas, sendo, portanto, a demanda muito superior a oferta até então existente.

A organização das ideias inovadoras para a administração/gestão na perspectiva da Escola Nova passou a ser compreendida dentro da visão da teoria clássica da administração proposta por Fayol e Taylor. Esse posicionamento reconfigurou o sistema educacional nacional incorporando outra dimensão em termos de acesso e oferta de ensino em 
diferentes modalidades e níveis. Ao compreender a instituição escolar como uma organização com objetivos definidos, a sistematização das rotinas e das ações criou padrões que foram incorporados tal qual um processo fabril.

Por outro lado, a concepção sociocrítica trouxe para a escola discussões que até então não eram pautadas dentro dos princípios organizacionais propostos no gerenciamento da rotina educacional. Segundo Abdian, Nascimento e Silva (2016), a partir dos anos 1980 o entendimento da administração/gestão escolar a partir de uma visão tecnocrática foi sendo substituída gradativamente pela perspectiva de que a educação é um ato político de transformação social e, portanto, a gestão escolar deveria caminhar nesse sentido. Os autores ainda destacam que nesse propósito de pensamento se enquadram autores como Vitor Paro, Miguel Arroyo e Maria de Fátima C. Felix. Para os autores a constatação da possibilidade da administração escolar se constituir como elemento importante para a transformação da sociedade adveio da desconstrução anterior que não diferenciava o processo pedagógico do processo fabril.

A participação da comunidade escolar no processo de decisão passou a ser um dos elementos centrais para se compreender uma concepção de organização escolar que preza pelo diálogo e pela participação popular, o que ficou conhecido como gestão democrática. Passou-se a compreender que há diferenças entre as organizações e que tais diferenças impactam no resultado final esperado.

De forma geral, podemos constatar que a mudança de paradigma da gestão empresarial para a gestão que considera a especificidade da escola, norteada pela teoria da gestão democrática, rompeu teoricamente com a ideia da semelhança entre as organizações, construiu referencial crítico para a análise da escola, mas conservou o modo de pensar a construção do conhecimento, qual seja a teoria da gestão (agora democrática) oferece ferramentas suficientes para a transformação da realidade (ABDIAN; NASCIMENTO; SILVA, 2016, p.729).

Segundo os autores, esse processo de mudança do paradigma organizacional da escola pública aconteceu em um momento de redemocratização da sociedade brasileira e constituiu-se como pilar para a solidificação da gestão democrática como referência e base da educação pública.

Passadas mais de duas décadas desde o processo de redemocratização brasileira, os objetivos da educação brasileira caminham ao mesmo tempo para resolver velhos e novos desafios. Com a possibilidade de transformação da escola em um ambiente de amplo aprendizado, não restrito apenas aos conteúdos programáticos da educação básica, e adentrando em ações voltadas para a aprendizagem ao longo da vida através de projetos orientados por modelos não-formais, a realidade organizacional da escola mudou, e 
com ela surge a necessidade de gestores adaptados a esses novos conceitos.

Nesse sentido, Abrucio (2010) afirma que a complexidade da organização escolar afeta o seu principal gestor, o diretor. Segundo o autor o gestor tem de aliar quatro tipos de competências: conhecimentos específicos à educação; o relacionamento interpessoal com a comunidade interna, em especial com os professores e alunos; a capacidade de ganhar confiança e atrair a comunidade externa, principalmente os pais e; habilidades em gestão. Tais competências vinculam-se aos estratos e relações políticas imbricados na estrutura escolar.

A atuação do gestor, portanto, está associada ao poder político ao qual se vincula. Isso quer dizer que não parece possível entender a ação administrativa isoladamente do poder que está sempre presente nela (SOUZA, 2012).

[...] o controle sobre o poder escolar garante a definição dos ideais sobre os quais se edificarão os processos de gestão e, ao mesmo tempo, a própria gestão é um processo de busca, conquista, disputa e/ou diálogo e socialização do controle desse poder de decisão sobre os rumos que a instituição segue (SOUZA, 2012, p.160).

Na nova configuração da escola pública, o entendimento do papel de novas alternativas educacionais como elemento facilitador para o processo construção da autonomia e emancipação dos alunos, requer por parte dos gestores habilidades de compreensão, análise e decisão sobre novas estratégias. Os estudantes necessitam de um local que os possibilite desenvolver não só o conteúdo curricular, mas também atividades diversas as quais possam exprimir suas habilidades (PORTELA, 2015). Esse princípio configura-se como um dos principais pilares para a ampliação da jornada escolar.

\section{GESTÃO DA AÇÃO E AS PERSPECTIVAS FRENTE OS PROJETOS DE CONTRATURNO}

De acordo com Luck (2015), os processos de gestão pressupõem a ação ampla e continuada que envolve múltiplas dimensões, tanto técnicas quanto políticas e que só se efetivam, de fato, quando articuladas entre si. Para a autora, a gestão educacional corresponde ao processo de gerir a dinâmica do sistema de ensino como um todo, isso incluiria, portanto, novas possibilidades educativas que vão além da oferta de educação tradicional.

Ainda nesse contexto, Luck (2014) infere uma relação próxima entre a gestão e a liderança ao elencar que a gestão nada mais é que um processo pelo qual se mobiliza e coordena o talento humano, coletivamente organizado, de modo que as pessoas em equipe possam promover resultados desejados. É do gestor da escola a responsabilidade 
máxima quanto à consecução eficaz da política educacional do sistema e desenvolvimento pleno dos objetivos educacionais, organizando e coordenando todos os esforços nesse sentido (LUCK, 2013).

O papel de organização das ACCs na escola, de acordo com a SEED (PARANÁ, 2012) fica a cargo do diretor, da equipe pedagógica e do próprio professor, através do envio de relatórios e acompanhamento via sistema próprio da secretaria. Tais ações devem ser desenvolvidas em turmas de no mínimo 25 alunos tendo prioridade de participação alunos em situação de vulnerabilidade social e que estejam participando do Programa Família Paranaense da Secretaria da Família e Desenvolvimento Social.

O programa está estruturado a partir de nove macrocampos nos quais os projetos são desenvolvidos. De acordo com a SEED (PARANÁ, 2011), a organização fica definida da seguinte forma: 1) Aprofundamento da Aprendizagem, 2) Experimentação e Iniciação Científica, 3) Cultura e Arte, 4) Esporte e Lazer, 5) Tecnologias da Informação, Comunicação e Mídias, 6) Meio Ambiente, 7) Direitos Humanos, 8) Promoção de Saúde, 9) Mundo do Trabalho e Geração de Renda. A oferta de determinado projeto deve estar enquadrado dentro dos macrocampos propostos, o que coloca a gestão escolar como elemento central para a correta condução do processo. A direta relação entre projeto proposto e qualificação docente necessária para sua execução é um dos elementos chave para a compreensão do processo decisório.

A forma como a escola é administrada tendo como base o modelo de gestão adotado pode influenciar a condução e os resultados educacionais obtidos mesmo quando há a inclusão de novas possibilidades educativas, tal qual a oferta de atividades complementares. A definição dos modelos de gestão segundo Libâneo et al (2008) é caracterizada a partir de quatro concepções:

- Concepção Técnico-Científica: com ênfase no processo de administração e burocratização rígida, esse modelo acentua a divisão do trabalho em níveis hierárquicos na escola havendo uma centralização do processo decisório na mão do gestor. A comunicação tende a ser linear.

- Concepção Autogestionária: gestão interna com elementos de autogestão social, tende a ter decisões tomadas dentro de um contexto coletivo. Exercício decisório pautado na auto-organização do grupo por meio de eleições e recusa a normas e sistemas de controle. Ênfase maior nas relações do que nas tarefas.

- Concepção Interpretativa: concebe a gestão como um processo onde a escola é uma realidade social subjetivamente construída. Valoriza as interpretações dos atores frente as percepções e significados subjetivos, valorizando o caráter humano ante o formal e estrutural normativo. 
- Concepção Democrático-Participativa: os objetivos sociopolíticos e pedagógicos da escola são definidos pela comunidade escolar. Foco na qualificação e competência profissional. Baseada na ideia de que "todos dirigem e são dirigidos, todos avaliam e são avaliados". A ênfase está tanto nas tarefas quanto nas relações.

A tomada de decisão do gestor frente às possibilidades de oferta educativa pode ter resultados distintos a partir da visão de gestão adotada pela escola. Tomando como referência o Art. 14 da LDB 9394/96 (BRASIL, 1996) que determina a gestão democrática como modelo a ser adotado, o papel da comunidade escolar é crucial para o sucesso da proposta pedagógica. Nesse sentido, o professor possui um papel imprescindível de mediador das prioridades e dos deveres didáticos da escola. É uma figura que conduz conhecimento, profissionalismo, deveres humanísticos e que também assume um compromisso de desempenho para com as propostas curriculares da entidade pedagógica em que se institui. Os professores, considerados como os principais agentes no processo educativo, têm sido criticados pela qualidade da educação que promovem e questionados em sua própria competência (RIOS, 1999, p. 86).

No que tange a elaboração dos projetos em contraturno escolar, é observada uma realidade que sugere um dilema perante a qualificação do profissional que desempenhará tal função. A vinculação das atividades de contraturno escolar junto às atividades curriculares dos vários componentes ainda não é clara. A ação do gestor escolar nesse caso é fundamental para articular diferentes propostas educativas dentro da escola. Diante deste prisma,

O processo de formação e aperfeiçoamento continuado dos professores da escola de educação básica, do ponto de vista crítico, deve articular o sistema educacional de forma orgânica, portanto, demanda a elaboração de um projeto político-pedagógico que perpasse os três níveis de ensino, permitindo alterar a qualidade da escola, tanto em termos de conteúdo, como em termos metodológicos, na perspectiva de um processo de democratização integrado em suas dimensões política, pedagógica e técnica. (ROSAR, 1999, p.160-161).

O Projeto Político Pedagógico (PPP) da escola, elaborado de forma conjunta, envolvendo a equipe gestora, professores, alunos e comunidade, pode ser compreendido como principal instrumento para orientar as diversas práticas pedagógicas existentes dentro da escola. De acordo com a SEED (PARANÁ, 2012), as atividades devem ser incluídas no PPP e atender aos marcos conceitual, situacional e operacional. O PPP deve ser entendido como um instrumento teórico-metodológico que visa ajudar a enfrentar os 
desafios do cotidiano da escola, de forma refletida, consciente, sistematizada, orgânica e participativa. É uma metodologia de trabalho que possibilita resignificar a ação de todos os agentes da instituição (VASCONCELLOS, 1995, p. 143).

Dessa maneira a vinculação das ACCs ao PPP da escola requer ações de articulação pedagógica e política que valorizem o papel de tais atividades como fator positivo no cotidiano escolar. No entanto, estudo de Ubinski e Strieder (2015) realizados também no Estado do Paraná, aponta que o desinteresse docente pelas atividades de contraturno ainda é forte e pode estar relacionado a diferentes fatores. Segundo as autoras, a direção escolar e os professores vêm se esforçando para reorganizar ambientes e superar dificuldades, porém, é sabido que a rotina docente é caracterizada por um excesso de atividades regulares e que a criação de projetos paralelos reforça tal argumento. O papel docente na elaboração das propostas também é apontado como um fator importante na condução do processo. Ubinski e Strieder (2015) relatam que o interesse da comunidade é o principal fator a ser observado, seguido da autonomia do professor para propor a atividade.

Assim, a função do gestor escolar, frente à coordenação de ações e organização sistemática das práticas pedagógicas deve estar orientada para promover a maximização dos resultados educacionais a partir de uma perspectiva que envolva o diálogo com o corpo docente e discente. Assume-se que o gestor escolar tem papel crucial na promoção de projetos de contraturno que valorizem o ambiente escolar. O gestor tem o papel de administrar e reger democraticamente e eficientemente as ações concebidas dentro da escola, dentre elas a execução de projetos desta natureza, já que, é o diretor que, de acordo com a lei, responde, em última instância, pelo bom funcionamento da escola onde se deve produzir um dos direitos sociais mais importantes para a cidadania (PARO, 2010, p. 766).

Compete ao gestor escolar a definição das ações administrativas a fim de se garantir insumos (tanto de natureza de recursos humanos quanto de materiais) necessários para o desenvolvimento das atividades escolares. Assim, o processo de avaliação de resultados é elemento central para a compreensão da importância de manutenção das ACCs. Tais atividades não podem ser compreendidas apenas como uma mera ação de ocupação de tempo livre, mas sim como instrumento articulador da aprendizagem proporcionada pelo sistema formal de ensino.

A perspectiva na implantação dos projetos de ACCs ao qual se articula a relação entre gestão e docência aponta para a importância da ligação estabelecida entre o aluno e comunidade. O professor responsável pelo projeto educacional de contraturno deve ver o aluno não somente como um sujeito que absorve conhecimento, mas também como aquele que compreende e transpõe o aprendizado que obteve naquele espaço e que também, intrinsicamente, trouxe conhecimento para o momento de sua realização. 
2 Como forma de preservação dos dados, o nome da cidade, das escolas e dos gestores foi omitido.

3 De acordo com o IBGE (2017), 94,5\% dos municípios brasileiros possuem menos que 100.00o habitantes sendo considerados municípios de pequeno porte.
Da mesma forma o gestor deve estar ativamente atento ao desenvolvimento das ACCs, proporcionando segurança administrativa e pedagógica aos docentes envolvidos. Não deve apenas ser um mediador de sua elaboração geral e de fornecimento de recursos, mas um planejador de iniciativas com vistas a melhoria dos padrões educacionais da unidade escolar. Articulação é a palavra chave que deve definir o papel do gestor frente ao modelo de ensino curricular tradicional de um lado e os projetos de atividades complementares curriculares de outro.

A proposta curricular da instituição, o cotidiano que a escola e a comunidade vivenciam, sejam eles tecnológicos, socioculturais, científicos ou econômicos, são fatores decisivos para o processo de tomada de decisão na elaboração de ações com vistas à implantação de projetos de ACCs. $\mathrm{O}$ engajamento do corpo docente e a visão da equipe gestora podem favorecer uma articulação efetiva de diversas ações educativas junto ao contexto escolar.

\section{METODOLOGIA}

A presente pesquisa foi realizada a partir de uma abordagem qualitativa com aporte de dados quantitativos com a finalidade de observar o desenvolvimento de projetos esportivos e de lazer em contraturno em escolas públicas estaduais em um município do interior do Paraná.

O município ${ }^{2}$ onde o estudo foi realizado possui segundo o IBGE uma população de 32.715 habitantes e um IDHM de 0,73. A escolha desse município ocorreu por dois fatores. O primeiro diz respeito à localização do campus da universidade proponente do estudo. O segundo e mais importante fator, diz respeito à característica do município. Com 32.715 habitantes o município é enquadrado como de pequeno porte, o que dentro do panorama brasileiro representa $94,5 \%$ dos municípios ${ }^{3}$.

O munícipio possui nove escolas estaduais com ACCs em atividade, no entanto, foram coletados dados completos de oito (8) mediante o fato de um gestor se recusar a participar do processo de entrevista. Foram obtidos, portanto, dados sobre o desenvolvimento das atividades no que tange aos macrocampos de ações, tipos de projetos e taxa de matrícula, bem como foram entrevistados os oito diretores escolares, entendidos aqui como principal gestor de ações do seio da escola. As entrevistas semiestruturadas com os gestores tiveram como finalidade a obtenção de informações sobre o processo de tomada de decisão e avaliação de impacto dos projetos no cotidiano escolar.

A pesquisa foi divida em duas fases de forma a obter o máximo de informações possíveis para traçar um panorama das ACCs nas escolas analisadas. A Fase 1 compreendeu o levantamento das informações quantitativas sobre os projetos desenvolvidos nas escolas estaduais como forma de triagem inicial. Nessa fase os dados foram coletados junto a base de dados do MEC ao qual são devidamente 
informadas pelas escolas junto ao Censo Escolar. Na Fase 2 foram realizadas entrevistas semiestruturadas com os gestores como forma de obter informações sobre o andamento dos projetos nas escolas a partir das especificidades de cada unidade. O roteiro foi pautado a partir de eixos centrais constituídos a priori para o entendimento do panorama organizacional das ACCs pela gestão escolar.

\section{RESULTADOS E DISCUSSÕES}

A localização geográfica das escolas no município indica que $77,8 \%(n=7)$ estão dispostas na área urbana e $22,2 \%(n=2)$ estão na área rural. Em relação a oferta de modalidade educacional, a predominância de $77,8 \%$ diz respeito à oferta do ensino fundamental e médio concomitante. Do total de escolas do município, $88,9 \%(n=8)$ ofertam ACCs na área de esporte e lazer, indicando uma forte presença de tais projetos na constituição do perfil de atividade complementar.

Como forma de compreensão do perfil das ACCs nas escolas e sua representatividade em relação ao universo total de alunos, é possível observar pela proporcionalidade de matrículas comparadas entre a educação básica e os projetos de ACCs que os números, em grande parte das escolas, são superiores a 50\%, como pode ser observado na tabela 1 .

Tabela 1 - Matrículas Escolares e Matrículas em Projetos de Contraturno

\begin{tabular}{cccc}
\hline Instituição & $\begin{array}{c}\text { Matriculas } \\
\text { Ed. Básica }\end{array}$ & $\begin{array}{c}\text { Matrículas } \\
\text { ACCs }\end{array}$ & \% Relativo \\
\hline Escola 1 & 294 & 231 & $78,57 \%$ \\
Escola 2 & 569 & 271 & $47,63 \%$ \\
Escola 3 & 476 & 169 & $35,50 \%$ \\
Escola 4 & 585 & 0 & - \\
Escola 5 & 442 & 627 & $141,86 \%$ \\
Escola 6 & 630 & 534 & $84,76 \%$ \\
Escola 7 & 74 & 222 & $300,00 \%$ \\
Escola 8 & 135 & 254 & $188,15 \%$ \\
Escola 9 & 25 & 61 & $244,00 \%$ \\
\hline
\end{tabular}

Fonte: Pesquisa Autores.

Destaca-se que o processo de matrícula em ACCs obedece ao critério de projeto, ou seja, um mesmo aluno pode estar matriculado em mais de um projeto sendo computado mais de uma vez no universo total. No entanto, os números são representativos, uma vez que atingem patamares elevados na grande maioria das escolas.

Com uma representatividade alta em relação às taxas de matrículas, a observação partiu no sentido de compreender quais os principais projetos de ACCs desenvolvidos, sendo possível constatar a variedade de opções de projetos como mostra a tabela 2. 
Tabela 2 - Principais Projetos de ACCs implantados

\begin{tabular}{lcccc}
\hline Área & F & \% & Matrículas & Média \\
\hline Línguas Estrangeiras & 8 & 13,8 & 275 & 34,3 \\
Futsal & 5 & 8,6 & 104 & 20,8 \\
Matemática & 4 & 6,9 & 290 & 72,5 \\
Outra categoria de Comunicação & 4 & 6,9 & 110 & 27,5 \\
Outra categoria de Esporte e Lazer & 4 & 6,9 & 186 & 46,5 \\
Org. de Coletivos para o Meio Ambiente & 3 & 5,2 & 194 & 64,6 \\
Teatro & 3 & 5,2 & 89 & 29,6 \\
Voleibol & 3 & 5,2 & 66 & 22,0 \\
Basquete & 2 & 3,4 & 47 & 23,5 \\
Leitura e Produção Textual & 2 & 3,4 & 100 & 50,0 \\
Língua Portuguesa & 2 & 3,4 & 190 & 95,0 \\
Outra cat. de Acompanhamento Pedagógico & 2 & 3,4 & 69 & 34,5 \\
Demais projetos & 16 & 27,7 & 749 & 46,8 \\
Total & 58 & 100,0 & 2469 & 42,5 \\
\hline
\end{tabular}

Fonte: Pesquisa autores

Os dados de desenvolvimento de projetos nas escolas e o percentual médio de matrículas segue a mesma tendência observada na pesquisa de Basei, Bendrath e Menegaldo (2017) em estudo das ACCs em cidades com mais de 100.00o habitantes, indicando uma tendência em termos de desenvolvimento dessa política.

A partir do diagnóstico quantitativo do universo de escolas em relação às ACCs, buscamos compreender como o processo de gestão de tais atividades é institucionalizado. Os dados foram coletados junto aos diretores a partir da realização de entrevistas semiestruturadas e o processo de análise obedeceu ao princípio de categorização temática a priori, sendo, portanto, constituídas 4 categorias centrais prévias a partir da fala dos sujeitos, sendo elas: 1) Papel do gestor, 2) Forma de seleção dos projetos de ACCs, 3) Recursos para as ACCs e, 4) Acompanhamento de ações.

A constituição dos eixos centrais foi definida a partir do disposto nos documentos que orientam o programa de ACCs no Estado. O papel do gestor, a forma de seleção dos projetos, a fonte de recursos e processo de acompanhamento e avaliação das ações são dispositivos presentes na Instrução normativa n. 07/2012 e na Resolução n. 1.690/2011 SEED-PR e fazem parte das orientações que balizaram o processo de gestão das ACCs nas escolas.

As análises das entrevistas pautaram-se em compreender as evocações de cada gestor a partir dos eixos centrais para observar como o processo de tomada de decisão para cada ação é compreendido. O quadro 1 ilustra as principais subcategorias evocadas a partir dos eixos centrais. 
Quadro 1 - Categorias e Subcategorias de análise

\begin{tabular}{|l|l|}
\hline \multirow{2}{*}{ Eixo Central (Categoria) } & Subcategorias evocadas \\
\hline \multirow{2}{*}{ E1: Papel do Gestor } & E1Sub1: Fiscalização \\
\cline { 2 - 2 } & E1Sub2: Acompanhamento \\
\cline { 2 - 2 } & E1Sub3: Organização \\
\hline \multirow{2}{*}{ E2: Forma de seleção dos projetos } & E2Sub1: Indução \\
\cline { 2 - 2 } & E2Sub2: Democrática \\
\hline \multirow{2}{*}{ E3: Recursos para as ACCs } & E3Sub1: Fundo complementar \\
\cline { 2 - 2 } & E3Sub2: Fundo regular \\
\hline \multirow{2}{*}{ E4: Acompanhamento de ações } & E4Sub1: Desresponsabilização \\
\cline { 2 - 2 } & E4Sub2: Burocrática \\
\hline
\end{tabular}

Fonte: pesquisa autores

As análises das entrevistas mostraram pluralidade de concepções a partir de cada eixo central debatido. Isso indica que o processo e modelo de gestão adotado pelas escolas não segue um mesmo padrão. Ao analisarmos a fala dos gestores a partir de cada eixo nota-se alinhamento a partir das subcategorias de evocação, sendo realizado um agrupamento temático de acordo com o discurso apresentado.

Quando observamos as falas dos sujeitos em relação ao Papel do gestor, observa-se um forte discurso centralizador das ações dentro de um processo decisório na escola.

[...] Meu... é... ofertar e depois acompanhar o desenvolvimento das atividades (Gestor A.D.) [...] eu fiscalizo (Gestor B.)

Todavia, é possível observar que há confusões em estabelecer conexões e articulações entre diferentes contextos de gestão, de um lado a estrutura da escola voltada para a educação básica, de outro, uma estrutura da escola voltada para projetos complementares ofertados em contraturno. Essa posição é bem exemplificada quando observamos a fala do Gestor I. que associa os projetos de ACCs como "matérias" e "conteúdos" dos professores.

[...] organiza tudo isso, organizar os professores os conteúdos em si é que pra que lado, e quais serão as questões que cada disciplina ou matéria que não é bem matéria na verdade (Gestor I.)

Também verificamos a imprecisão entre a vinculação das ACCs ao universo da escola. De acordo com a Instrução n. 07/2012 as ACCs vinculam-se aos projetos pedagógicos das escolas no intuito de fomentar o desenvolvimento qualitativo do ensino e a continua expansão do tempo de permanência escola, porém, alguns gestores associam as ACCs ao currículo tradicional da escola, como pode ser observado nas falas dos gestores J.M. e S.B. 
As atividades complementares fazem parte do currículo então o mesmo trabalho que a gente desenvolve como gestor do ensino regular a gente também desenvolve nas ACCs (Gestor J. M.)

Então nós temos feito um trabalho de enriquecimento é do currículo através das atividades complementares (Gestor S. B.)

A construção de uma ação educativa ampla na qual as ACCs tem papel auxiliar no processo de melhoria da educação é prerrogativa da política instituída na Res. n. 1.690/2011 SEED. Nesse sentido, de acordo com Dourado (2007), a busca por melhoria da qualidade da educação exige medidas não só no campo do ingresso e da permanência, mas requer ações que possam reverter a situação de baixa qualidade da aprendizagem na educação básica. Construir uma nova proposta e articulá-la com o PPP é tarefa árdua que precede de um sistema relacional e de articulação interna muito forte entre os atores da escola. Tal proposição com foco em inovação no uso das ACCs como mecanismo auxiliar demanda compreender o que Veiga (2003) aponta, ao falar em inovação e projeto político-pedagógico tem sentido se não esquecermos qual é a preocupação fundamental que enfrenta o sistema educativo: melhorar a qualidade da educação pública para que todos aprendam mais e melhor.

Quando indagados sobre a Forma de Seleção dos projetos de ACCs, a diversidade das respostas indicou que não há um padrão pré-estabelecido que permita compreender, do ponto de vista da gestão, como a oferta de tais atividades se relaciona com os pressupostos de qualidade educacional proposto pela Instrução n. 07/2012. O princípio de um pluralismo de ideias, pautado na coletividade e participação de uma construção coletiva, tal qual apontado por Paro (2006, 2010), Dourado (2007) e Souza (2009) se mostraram pouco evidentes nas falas dos gestores.

Alguns gestores focam o processo decisório a partir do perfil da escola, o que levaria em consideração o espaço físico, materiais e recursos humanos, como é o caso dos gestores A.D., B. e S.B.

[...] Por aptidão da escola... característica (Gestor A. D.)

[...] De acordo com o publico de interesse e as atividades que provoquem mais interesse nos alunos na permanência e estabilidade dentro da escola (Gestor B.)

[...] Nós selecionamos através de consulta a comunidade e de acordo com a realidade da instituição (Gestor S. B.)

Verificamos também a existência de unidade escolar em que não há sequer um único critério para a decisão de 
implantação de projetos, o que organizacionalmente torna-se um fator complicador dentro do ambiente escolar.

[...] não existe assim um critério específico (Gestor N. P.)

Há pouca ou nenhuma relação direta, nesse caso, com um princípio de gestão democrática na escola. A participação da comunidade escolar de acordo com as falas dos gestores aparece limitada e pouco ativa dentro de um processo de tomada de decisão para atividades (ACCs) cujo viés tende a ser flexível a partir dos anseios e interesses locais.

A reprodução de um padrão organizacional centralizador também se configurou como base em relação à gestão de ACCs nas escolas analisadas, tal qual o apontado por Neto e Castro (2011). Segundo os autores, a adoção de uma gestão democrática exige mudanças substanciais nas organizações escolares e nas pessoas que nelas trabalham, considerando que o que tem prevalecido, historicamente, em nossas escolas, no geral, são práticas de gestão com características centralizadoras (NETO, CASTRO, 2011, p.753).

Quando o assunto é voltado para a compreensão de como as escolas obtém Recursos para ACCs, não há consenso e a diversificação das informações passadas nos leva a compreender que as fontes de recursos obtidas pelas escolas que ofertam ACCs são efetivamente desconhecidas pelos gestores. APMF,

Alguns gestores vinculam os recursos ao MEC e

[...] A fonte é do PDDE né vem diretamente do MEC né são recursos que vem do MEC (Gestor I.)

As fontes são as fontes normais da escola, fundo rotativo, temos a APMF (Gestor A. D.)

[...] Atualmente a gente consegue suprimir todas as necessidades através da verba que vem da educação regular, porém os projetos não recebem uma verba mais específica a não ser o Mais Educação, que recebe uma verba boa do governo federal (Gestor B.)

[...] No caso dessa instituição nós não temos nenhuma fonte complementar, então é, alguns projetos são desenvolvidos em instituições através do Programa Mais Educação, para essas escolas existe uma um recurso viabilizado pelo governo federal pra manter esses projetos (Gestor S. B.)

Enquanto outro gestor não especifica a fonte,

[..] As fontes de recurso são as mesmas que vão para as escolas (Gestor N. P.) 
Nenhum dos gestores soube, de maneira exata citar a fonte de recurso para a manutenção das atividades propostas para as ACCs. Essa ausência de clareza sobre as fontes de recursos mostra uma situação preocupante, uma vez que, a organização administrativa e financeira de tais atividades depende de uma correta alocação de recursos para o alcance dos seus objetivos fins aos quais foram propostas. A Instrução Normativa n. 07/2012 é clara em seu item X, itens 1 e 2, ao elencar que haverá recursos específicos para tais atividades via Fundo Rotativo das escolas e que o uso do mesmo deverá obedecer as normas previstas para aplicação e prestação de contas no que tange ao uso de recursos desse fundo.

Quando não há clareza sobre as fontes de recursos e quais seus números, a possibilidade de gerenciamento de insumos e processos dentro do ambiente administrativo torna-se uma tarefa árdua, o que pode impactar diretamente no Acompanhamento de Ações dos projetos nas escolas.

Dentro de um ambiente onde as rotinas organizacionais demandam um processo sistematizado de planejamento, organização, direção e controle, o acompanhamento das ações propostas a partir das perspectivas das ACCs torna-se ferramenta essencial para a correção de fluxo e direcionamento das iniciativas com vistas a assegurar que se cumpra com os objetivos propostos.

A desresponsabilização das ações nesse momento do processo organizacional escolar ficou evidente na fala de alguns gestores. Parte dos entrevistados delegam tais iniciativas a outros atores do processo como pode ser observado nas seguintes falas:

[...] Ele é acompanhado sempre pelo um pedagogo (Gestor A. D.)

[...] As pedagogas, a gente destina sempre uma pedagoga pra ficar acompanhando junto com eles, a gente faz reuniões provavelmente de quinze em quinze dias (Gestor B.)

[...] a gente tem o acompanhamento pedagógico, tem um o pedagogo específico para essa função que acompanha certinho (Gestor J.M.)

Por outro lado, também foi possível observar gestores que conhecem o processo de acompanhamento das ACCs pela SEED e organizam as atividades de acompanhamento a partir de uma rotina estritamente técnica-burocrática.

[...] Esse é um acompanhamento muito específico. Nós acompanhamos através de nosso sistema chamado registro de classe online, verificamos qual é a atividade que vai ser trabalhada durante as semanas, o professor tem que apresentar um planejamento de 
seis em seis meses do que ele vai fazer e nós acompanhamos principalmente a questão da presença e saber se os alunos realmente estão se interessando (Gestor B.)

[...] a cada final de semestre, nós inserimos os projetos no sistema, a proposta pedagógica a cada final de semestre nós também fazemos um relatório pedagógico de como está o funcionamento, além disso, o acompanhamento dos próprios técnicos do núcleo de educação que fazem a verificação em bloco do desenvolvimento dos projetos (Gestor S. B.)

A ausência de envolvimento com ações de natureza pedagógica direta coloca o gestor como um mero cumpridor de atividades burocráticas, posicionando-o com um ator muitas vezes alheio ao processo educativo sob sua tutela. De acordo com Neto e Castro (2011) esse é um modelo padrão da administração pública brasileira. Para os autores, a gestão nestas unidades, baseada em um modelo de administração caracterizado pela hierarquização, verticalização dos sistemas, burocratização dos processos e realizada, predominantemente, mediante o controle, não atende mais aos novos requerimentos do atual contexto social.

\section{CONSIDERAÇÕES FINAIS}

A partir do entendimento das bases que fundamentam a administração/gestão educacional na escola pública brasileira, observamos a partir dos dados coletados que uma nova configuração do processo organizacional está em curso tendo como perspectiva a ampliação da jornada escolar a partir da incorporação de projetos de contraturno.

Assim como os resultados da pesquisa de Basei, Bendrath e Menegaldo (2017), verificamos que as ACCs como proposta embrionária de uma educação em tempo integral como política em construção assume evidências concretas de sua importância pelos números absolutos de matrícula e implantação de projetos no município analisado.

Neste contexto, o papel do gestor escolar como ator responsável pela organização e acompanhamento das ações pedagógicas o posiciona em um patamar onde a compreensão das novas perspectivas pedagógicas, bem como o direcionamento do ato educativo orientado pela necessidade de resultados educacionais se faz não só necessário como prioritário. Nas escolas analisadas os dados empíricos mostraram que essa ainda é uma realidade distante. Há uma latente ausência de objetivos articulados para os projetos de contraturno escolar, uma vez que, apesar dos altos índices de participação dos alunos, a organização didática não estabelece vínculos concretos com a proposta pedagógica das escolas.

A atuação do gestor escolar a partir de seu entendimento de funcionamento do programa de ACCs ainda é 
deficitário e limitado como mostraram as entrevistas. Há divergências em termos elementares de configuração das ACCs nas escolas, como a compreensão da fonte de recurso orçamentário e do processo de acompanhamento e indicação de projetos. Isso mostra uma desarticulação entre o proposto pela SEED e o que realmente se configura no universo escolar, uma vez que, a informação ou desinformação do gestor é uma variável decisiva na sistematização do processo com vistas a objetivos determinados.

Com uma ausência de critérios para a definição dos projetos em contraturno escolar, a política da SEED determinada pela Instrução n. 07/2012 não consegue definir as atividades complementares curriculares como elemento constitutivo direto, já que, a participação dos gestores no acompanhamento das ações, definição de projetos e organização financeira se torna complexa pela ausência clara de um entendimento direto de tal proposta como pode ser observado nas falas dos gestores.

Os dados indicaram que papel do gestor escolar enquanto articulador de diversas possibilidades educativas na escola, ainda não se consolidou. A fala dos gestores mostra que a relação entre a proposta pedagógica da escola e a proposta das ACCs não está clara na maioria das escolas, o que dificulta a obtenção de melhores resultados.

Portanto, a amplitude das ações propostas em termos de projetos, bem como a proporcionalidade de participação por escola em relação às matrículas do ensino formal, traduz que, há uma intencionalidade em ofertar projetos cuja demanda atenda aos interesses da comunidade escolar, mesmo que o processo de escolha não seja claro ou tenha critérios definidos a partir da gestão escolar. $\mathrm{O}$ grau de participação dos alunos também caminha no sentido de valorizar a iniciativa dos projetos em contraturno escolar, indicando que a gestão escolar não pode ignorar ou subvalorizar iniciativas educacionais paralelas ao modelo tradicional já ofertado.

\section{REFERÊNCIAS}

ABDIAN, Graziela Zambão; NASCIMENTO, Paulo Henrique Costa; SILVA, Nathália Delgado Bueno da. Desafios teórico-metodológicos para as pesquisas em administração/gestão educacional/escolar. Educ. Soc., Campinas, v. 37, n. 135, p.465-480, abr./jun. 2016.

ABRUCIO, Fernando Luiz. Gestão escolar e qualidade da educação: um estudo sobre dez escolas paulistas. Estudos \& Pesquisas Educacionais. Fundação Vitor Civita, 2010, pp. 241-274.

BASEI, Andreia Paula; BENDRATH, Eduard Angelo; MENEGALDO, Pedro Henrique Iglesiaz. Atividades complementares curriculares em contraturno escolar no estado 
do Paraná: um estudo do macrocampo esporte e lazer. Motrivivência, Florianópolis/SC, v. 29, n. 51, p. 136-156, jul./2017.

BRASIL. Lei 9.394, de 20 de dezembro de 1996: Lei de Diretrizes e Bases da Educação Nacional. Senado Federal. Secretaria Especial de Editoração e Publicações. Subsecretaria de Edições Técnicas. Brasília. 1996.

DOURADO, Luiz Fernandes. Políticas e gestão da educação básica no brasil: Limites e perspectivas. Educação \& Sociedade, Campinas, v. 28, n. 100 - Especial, p. 921-946, out. 2007.

DRABACH, Neila Pedrotti; MOUSQUER, Maria Elizabete Londero. Dos primeiros escritos sobre Administração escolar no Brasil aos escritos sobre gestão escolar: Mudanças e continuidades. Currículo sem Fronteiras, v. 9, n. 2, pp. 258-285, jul./dez. 2009.

LIBANEO, Jose Carlos et al. Educação Escolar: políticas, estrutura e organização. 6. ed. São Paulo: Cortez, 2008.

LUCK, Heloisa. Gestão Educacional. Uma questão paradigmática. 12. ed. Petrópolis, RJ: Editora Vozes, 2015.

. Liderança em gestão escolar. 9. ed. Petrópolis, RJ: Editora Vozes, 2014.

. Ação Integrada: Administração, supervisão e orientação educacional. 29. ed. Petrópolis, RJ: Editora Vozes, 2013.

Dimensões da gestão escolar e suas competências. Curitiba: Editora Positivo, 2009.

NETO, Antônio Cabral; CASTRO, Alada Maria Duarte Araújo. Gestão escolar em instituições de ensino médio: entre a gestão democrática e a gerencia. Cadernos Cedes, Campinas, v. 23, n. 61, p. 267-281, dez. 2003.

PARANÁ. Secretaria do Estado da Educação. Superintendência da Educação. Instrução n. Oo7/2012-SEED/ SUED. Dispõe sobre o Programa de Atividades Complementares Curriculares em contraturno, nas instituições de ensino da Rede Estadual. Paraná, 2012.

PARANÁ. Secretaria do Estado da Educação. Superintendência da Educação. Resolução n. 1.690 de 27 de Abril de 2011. Publicado no Diário Oficial $n^{\circ} .8472$ de 24 de Maio de 2011.

PARO, Vitor. Henrique. A educação, a política e a administração: reflexões sobre a prática do diretor de escola. Educação e Pesquisa, São Paulo, v. 36, n.3, p. 763-778, set./dez. 2010. 
PARO, Vitor Henrique. Gestão democrática da escola pública. 3. ed. São Paulo: Ática, 2006.

RIOS, Terezinha. Ética e competência. 8. ed. São Paulo: Cortez, 1999.

ROSAR, Maria de Fátima Félix F. F. A dialética entre a concepção e a prática de gestão democrática no âmbito da educação no Brasil. Educação \& Sociedade, v. 20, n. 69, pp. 165-176, dez. 1999.

SANDER, Benno. A pesquisa sobre política e gestão da educação no Brasil: uma leitura introdutória de sua construção. Revista Brasileira de Política e Administração da Educação, v. 23, n. 03, p. 421-447, set./dez. 2007.

SANDER, Benno. Gestão da Educação na América Latina: construção e reconstrução do conhecimento. São Paulo: Autores Associados, 1995.

SOUZA, Angelo Ricardo de. A natureza política da gestão escolar e as disputas pelo poder na escola. Revista Brasileira de Educação, v. 17, n. 49, jan./abr. 2012.

SOUZA, Angelo Ricardo de. Explorando e construindo um conceito de Gestão escolar democrática. Educação em Revista. Belo Horizonte, v. 25, n. 03, p.123-140, dez. 2009.

UBINSKI, Juliana Alves da Silva; STRIEDER, Dulce Maria. O (Des)Interesse dos Professores Frente às Atividades em Contraturno. Revista Electrónica Actualidades Investigativas en Educación. Costa Rica, v.15, n.1, jan./abr. 2015, pp.1-18. DOI: dx.doi.org/10.15517/aie. v15i1.17200

VASCONCELlOS, Celso dos Santos. Planejamento: plano de ensino-aprendizagem e projeto educativo. São Paulo: Libertat, 1995.

VEIGA, Ilma Castro Alemcastro. Inovações e projeto político-pedagógico: Uma relação regulatória ou emancipatória? Cadernos Cedes, Campinas, v. 23, n. 61, p. 267-281, dez. 2003 . 